\title{
Desempenho de plantas de cobertura em sobressemeadura na cultura da soja
}

\author{
Leandro Pereira Pacheco( ${ }^{(1)}$, Fábio Ribeiro Pires ${ }^{(2)}$, Fernando Pereira Monteiro(3), Sérgio de Oliveira Procópio(4), \\ Renato Lara de Assis ${ }^{(3)}$, Marcos Lima do Carmo ${ }^{(3)}$ e Fabiano André Petter ${ }^{(1)}$
}

\begin{abstract}
(1)Universidade Federal de Goiás, Escola de Agronomia, Rodovia Goiânia-Nova Veneza, Km 0, Campus II, CEP 74001-970 Goiânia, GO. E-mail: leandroppacheco@terra.com.br, fabianopetter@brturbo.com.br (2)Universidade Federal do Espírito Santo, Faculdade de Agronomia, Centro Universitário Norte do Espírito Santo, Rua Humberto de Almeida Francklin, no 257, Bairro Universitário, CEP 29933-480 São Mateus, ES. E-mail: fabiopires@ceunes.ufes.br (3)Fesurv, Universidade de Rio Verde, Faculdade de Agronomia, Caixa Postal 104, CEP 75901-970 Rio Verde, GO. E-mail: fernandopereiram@bol.com.br, assis@fesurv.br, marcoslima@fesurv.br (4)Embrapa Tabuleiros Costeiros, Avenida Beira Mar, no 3.250, Praia 13 de Julho, CEP 49025-040 Aracaju, SE. E-mail: soprocopio@gmail.com
\end{abstract}

Resumo - O objetivo deste trabalho foi avaliar a capacidade de estabelecimento de plantas de cobertura em sobressemeadura na cultura soja. A soja foi semeada em diferentes épocas para que, no estádio $\mathrm{R}_{7}$ (maturação fisiológica), ocorressem diferentes condições climáticas para implantação das plantas de cobertura. O experimento foi realizado em Rio Verde, GO, na safra de verão 2005/2006, em Latossolo Vermelho distroférrico. Foram avaliadas seis plantas de cobertura: Brachiaria brizantha, B. ruziziensis, B. decumbens, Eleusine coracana, Pennisetum glaucum e o híbrido Cober Crop [Sorghum bicolor (L.) Moench x Sorghum sudanense Piper Stapf], e uma testemunha mantida em pousio. A soja foi semeada em quatro épocas: 27/10/2005, 10/11/2005, 24/11/2005 e 14/12/2005. A sobressemeadura das plantas de cobertura foi realizada manualmente, a lanço, quando a soja atingiu o estádio $\mathrm{R}_{7}$. Com exceção da segunda época de semeadura da soja, que apresentou a menor média de estande em todas as plantas de cobertura, em razão da maior matocompetição, todas as demais possibilitaram crescimento inicial satisfatório das plantas de cobertura sobressemeadas em $\mathrm{R}_{7}$, com base na emergência, altura de plantas, cobertura do solo e produção de palhada. B. ruziziensis, B. brizantha, B. decumbens e o híbrido Cober Crop apresentam maior potencial para a produção de palhada durante a entressafra no Cerrado, com uso da sobressemeadura.

Termos para indexação: Brachiaria, Eleusine coracana, Pennisetum glaucum, Cober Crop, integração lavourapecuária, plantio direto.

\section{Performance of cover crops oversown onto soybean}

\begin{abstract}
The objective of this work was to evaluate the establishing capacity of cover crops, oversown onto soybean. The soybean was planted at different seasons, so that in the $\mathrm{R}_{7}$ stage (physiologic maturation) different climatic conditions would be present for cover crop implantation and growth. The experiment was carried out in Rio Verde, GO, Brazil, in the summer crop season 2005/2006, on a Rhodic Ferralsol. Six cover crops were evaluated: Brachiaria brizantha, B. ruziziensis, B. decumbens, Eleusine coracana, Pennisetum glaucum, and the hybrid Cober Crop [Sorghum bicolor (L.) Moench x Sorghum sudanense Piper Stapf]. Fallow treatment was used as control. Soybean was planted at four sowing seasons: 10/27/2005, 11/10/2005, 11/24/2005 and 12/14/2005. Oversowing was carried out manually, by broadcasting at the $\mathrm{R}_{7}$ stage of soybean. Except for the second sowing season, in which weed competition reduced the mean stand of cover crops, all the remaining sowing seasons of soybean resulted in satisfactory initial cover crop growth, as given by: emergence, crop height, soil cover, and biomass accumulation. Oversowing with B. ruziziensis, B. brizantha, B. decumbens and the hybrid Cober Crop show higher potential to produce mulch, during the off-season in Cerrado.
\end{abstract}

Index terms: Brachiaria, Eleusine coracana, Pennisetum glaucum, Cober Crop, crop-livestock integration, no-till.

\section{Introdução}

A formação e manutenção de cobertura do solo, nas condições edafoclimáticas do Cerrado, constitui-se em grande desafio em razão da elevada taxa de decomposição dos resíduos vegetais, mesmo no sistema plantio direto (SPD) com inverno seco (Alves et al., 1995; Ceretta et al., 2002). A taxa de decomposição pode 
ser de cinco a dez vezes mais acelerada em regiões tropicais e subtropicais do que em regiões temperadas (Lal \& Logan, 1995). Além disso, o deficit hídrico que ocorre na entressafra restringe o cultivo de espécies para formação de palhada na safrinha, ou logo antes da safra (cultivo de primavera), com semeadura dos cultivos de cobertura no início do período chuvoso (Alvarenga et al., 1995; Amabile et al., 2000).

Torres et al. (2008) cultivaram plantas de cobertura antes da safra e na safrinha, no Cerrado, e observaram que, com exceção do milheto (Pennisetum glaucum), as demais espécies não atingiram acúmulo satisfatório de palhada. Boer et al. (2007), em estudo que avaliou a ciclagem de nutrientes no Cerrado, pelo uso de plantas de cobertura semeadas na safrinha, mostraram que a maioria dos nutrientes é liberada de forma precoce para aproveitamento da safra seguinte, em razão da acelerada decomposição dos resíduos vegetais. Para compensar essa defasagem, torna-se necessário uso de técnicas que aumentem o acúmulo de fitomassa por parte das plantas de cobertura (Kliemann et al., 2006) e que sincronizem a decomposição da palhada e a taxa de liberação dos nutrientes com a demanda das culturas anuais semeadas em sucessão (Gama-Rodrigues et al., 2007).

Uma das opções para consolidar o SPD é a integração lavoura-pecuária (ILP). No entanto, a maior parte das áreas cultivadas no Centro-Oeste é ocupada pela soja, que não apresenta a mesma performance do milho em consórcio com plantas de cobertura (Kluthcouski \& Aidar, 2003). A soja apresenta mecanismo $\mathrm{C}_{3}$ de fixação de carbono, e acumula menor fitomassa do que o milho, além de apresentar desenvolvimento mais lento. Essas características conferem menor capacidade competitiva à leguminosa, em relação à gramínea, e constituem-se no principal fator do insucesso da soja em cultivos consorciados (Portes et al., 2000). O uso de subdoses de graminicidas, em pós-emergência da soja, possibilita reduzir o crescimento inicial da planta de cobertura em relação à soja. Entretanto, em razão da baixa altura de corte da plataforma da colhedora, necessária a esta cultura, recomenda-se uso de dessecantes pré-colheita, para possibilitar a colheita mecanizada, o que pode inviabilizar o desenvolvimento das plantas de cobertura durante a entressafra (Silva et al., 2006).

Tem-se difundido, como alternativa para a formação de palhada em sucessão à cultura da soja, a sobressemeadura de plantas de cobertura, por ocasião do estádio $\mathrm{R}_{7}$, na maturidade fisiológica da soja, que é o início da desfolha. O sucesso dessa tecnologia depende das condições climáticas, na véspera da semeadura, e da capacidade de germinação e crescimento da planta de cobertura em superfície.

Os trabalhos de Lara-Cabezas (2004), com sementes peletizadas de milheto, e de Trecenti (2005) apontaram a sobressemeadura como alternativa viável para solucionar a formação e a manutenção de palhada, em SPD no Cerrado. No entanto, para consolidação dessa tecnologia, é necessário que se avaliem e selecionem espécies que apresentem boa adaptação ao cultivo consorciado, não prejudiquem a cultura principal, sejam tolerantes à deficiência hídrica (Lara-Cabezas, 2004), produzam elevada quantidade de fitomassa para a cobertura do solo (Perin et al., 2004) e, se possível, apresentem aptidão para forragem.

Existem diversos questionamentos sobre as condições que otimizam o emprego da sobressemeadura, como a quantidade ideal de sementes e o comportamento da planta de cobertura sobressemeada em diferentes épocas, o que está condicionado à época de implantação da soja, cujo atraso implicará em maior risco climático para o desenvolvimento das plantas de cobertura consorciadas.

O objetivo deste trabalho foi avaliar a capacidade de estabelecimento de plantas de cobertura em sobressemeadura, na cultura soja, implantada em diferentes épocas, para a formação de palhada para o SPD, no Cerrado.

\section{Material e Métodos}

O experimento foi realizado na área experimental do Campus Universitário da Fesurv, Universidade de Rio Verde, em Goiás (a $17^{\circ} 48^{\prime} \mathrm{S}, 50^{\circ} 55^{\prime} \mathrm{W}$, e altitude de $760 \mathrm{~m}$ ), de outubro de 2005 a outubro de 2006, em Latossolo Vermelho distroférrico, com relevo suaveondulado e declividade de 4\%. A área foi cultivada com soja, em sistema plantio direto no verão, e pousio na entressafra, por três anos. A análise química do solo, coletada na camada de 0-20 cm, apresentou: $\mathrm{pH}\left(\mathrm{CaCl}_{2}\right)$ 5,6; $\mathrm{Ca}, \mathrm{Mg}, \mathrm{Al}$ e $\mathrm{H}+\mathrm{Al}$ de 2,11, 1,43, 0,05 e $4 \mathrm{cmol}_{\mathrm{c}} \mathrm{dm}^{-3}$, respectivamente; $\mathrm{K}$ e $\mathrm{P}$ com 140 e $3,66 \mathrm{mg} \mathrm{dm}^{-3}$, respectivamente; CTC e SB com 7,94 e 3,90 $\mathrm{cmol}_{\mathrm{c}} \mathrm{dm}^{-3}$, respectivamente; $\mathrm{V}(\%)$ 49,1; matéria orgânica, areia, silte e argila, 22, 310, 150 e $540 \mathrm{~g} \mathrm{~kg}^{-1}$, respectivamente.

Foram avaliadas seis plantas de cobertura: Brachiaria brizantha (braquiarão), B. ruziziensis (ruziziensis), 
B. decumbens (capim-braquiária), Eleusine coracana (capim-pé-de-galinha), Pennisetum glaucum (milheto ADR500) e Cober Crop [híbrido de sorgo Sorghum bicolor (L.) Moench e capim-sudão Sorghum sudanense Piper Stapf], e uma testemunha (vegetação espontânea). A testemunha foi composta predominantemente por: Alternanthera tenella (apagafogo), Cenchrus echinatus (timbete) e Commelina benghalensis (trapoeraba).

A soja foi semeada em quatro épocas: 27/10/2005, 10/11/2005, 24/11/2005 e 14/12/2005, em SPD, o que resultou em quatro épocas de sobressemeadura das plantas de cobertura, que ocorreram em: 30/1/2006, 13/2/2006, 22/2/2006 e 14/3/2006. A sobressemeadura foi realizada manualmente, a lanço, quando a soja atingiu o estádio $\mathrm{R}_{7}$ (início da desfolha na maturação fisiológica), em média, 30 dias antes da colheita. $\mathrm{O}$ delineamento utilizado foi o de blocos ao acaso, em esquema de parcelas subdivididas, com o fator época de sobressemeadura na parcela principal e o fator plantas de cobertura nas subparcelas, com quatro repetições.

Para a semeadura da soja cultivar Monsoy 6101, de ciclo precoce (110 dias na região de Rio Verde, GO), a área foi dessecada com glifosato $\left(640 \mathrm{~g} \mathrm{ha}^{-1}\right), 15$ dias antes de cada época de semeadura da soja. A soja foi semeada com semeadora pneumática de precisão para SPD, com sete linhas espaçadas em $0,45 \mathrm{~m}$, com população de 467 mil plantas ha ${ }^{-1}$, o que corresponde a 21 plantas por metro. A adubação foi realizada com $400 \mathrm{~kg} \mathrm{ha}^{-1}$ da fórmula 2-20-18 (NPK). As parcelas foram constituídas por sete linhas da cultura $(3,5 \mathrm{~m}) \mathrm{e}$ $35 \mathrm{~m}$ de comprimento, divididas em sete subparcelas (plantas de cobertura), cada uma com cinco metros de comprimento. A área útil das subparcelas foi composta pelas cinco linhas centrais, tendo-se descontado um metro de cada lado, no sentido do comprimento $\left(6,75 \mathrm{~m}^{2}\right)$. A soja foi colhida manualmente, após a maturação fisiológica completa.

As quantidades de sementes, para a sobressemeadura das plantas de cobertura a lanço, foram quatro vezes superiores às quantidades recomendadas para a semeadura em linha (Trecenti, 2005) e foram determinadas com base no valor cultural (VC) de cada espécie. Assim, utilizaramse 24, 24, 24, 34, 70 e $40 \mathrm{~kg} \mathrm{ha}^{-1}$ - com VC de 32, 32, 32, 70,80 e $90 \%$ - de B. brizantha, B. ruziziensis, B. decumbens, Eleusine coracana, Pennisetum glaucum e híbrido Cober Crop, respectivamente. As informações de precipitação e temperatura, no período de condução do trabalho, estão representadas na Figura 1.

Aos 15 e 30 dias após a sobressemeadura (DAS), foi determinado o estande de plantas em área de $0,5 \times 0,5 \mathrm{~m}$ $\left(0,25 \mathrm{~m}^{2}\right)$, com duas amostragens aleatórias por subparcela. A altura das plantas de cobertura foi medida em nove plantas, na área útil de cada parcela, aos 30 DAS. Essas duas variáveis não foram determinadas na testemunha.

A cobertura de solo foi determinada aos 30 e 75 DAS e, também, na primeira quinzena de setembro de 2006, aos 230, 217, 208 e 188 DAS, e na segunda quinzena de outubro de 2006, aos 260, 247, 238 e 218 DAS, para a primeira, segunda, terceira e quarta épocas de semeadura da soja, respectivamente. Essa avaliação foi realizada com duas leituras de forma aleatória nas parcelas, seguindo a metodologia descrita por Stocking (1988). As medições foram realizadas por meio de um aparato de madeira, que consistia em uma estrutura com duas barras horizontais ao solo (inferior e outra superior), suspensas a $1,5 \mathrm{~m}$ de altura do solo. Cada uma das barras horizontais apresentava 20 orifícios coincidentes, com diâmetro de $2 \mathrm{~mm}$, espaçados em $10 \mathrm{~cm}$, pelos quais foram efetuadas as visadas. Sempre que a observação de um orifício coincidia com a presença de fitomassa da planta de cobertura, era registrada a presença de cobertura. A cobertura de cada parcela foi calculada, e contabilizouse a percentagem média, em duas repetições, de orifícios com presença de plantas de cobertura.

Para a avaliação de fitomassa fresca e fitomassa seca, coletaram-se plantas inteiras, seccionadas rente ao solo, em número de três subamostras, com o uso de um quadrado de ferro de $0,5 \times 0,5 \mathrm{~m}$. As amostras foram imediatamente pesadas para obtenção da fitomassa fresca. Em seguida, foram secadas em estufa, com circulação forçada de ar, por 72 horas a $65^{\circ} \mathrm{C}$, e pesadas para obtenção da fitomassa seca. Essas determinações

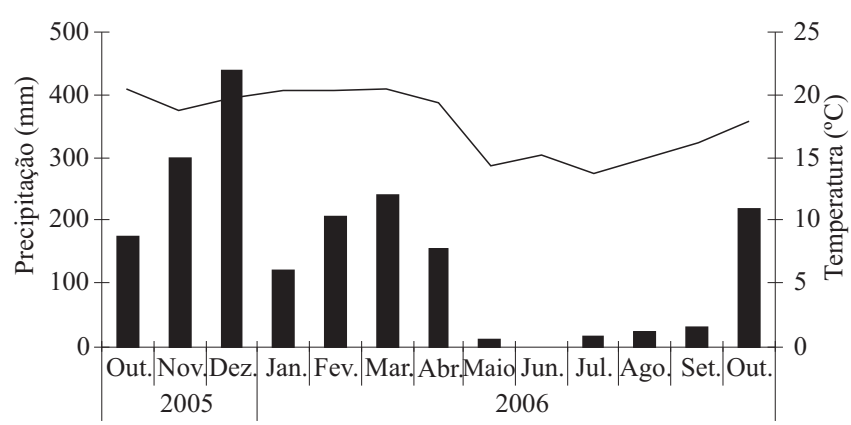

Figura 1. Precipitação mensal (ם) e temperatura média (-), no período de condução do experimento. 
foram realizadas: na primeira quinzena de maio de 2006, aos $100,87,78$ e 58 DAS; na segunda quinzena de junho de 2006, aos 140, 127, 118 e 98 DAS; e na segunda quinzena de outubro de 2006, aos 260, 247, 238 e 218 DAS, respectivamente para a primeira, segunda, terceira e quarta épocas de semeadura da soja.

Os resultados foram submetidos à análise de variância e, quando pertinente, as médias foram comparadas pelo teste de Tukey, a 5\% de probabilidade.

\section{Resultados e Discussão}

A cultura da soja apresentou produtividade média de 2,95 $\mathrm{Mg} \mathrm{ha}^{-1}$, sem efeito significativo dos tratamentos, já que a sobressemeadura das plantas de cobertura foi feita na maturação fisiológica da soja, e a interferência do consórcio tardio na produtividade de grãos é nula, principalmente porque a colheita das parcelas foi manual. Na maturação fisiológica, a soja já tem definida sua produtividade. Além disso, o crescimento das plantas de cobertura somente se iniciou depois de elevada taxa de desfolha da soja, quase no ponto de colheita.

$\mathrm{Na}$ emergência das plantas de cobertura, verificou-se interação significativa entre os fatores plantas de cobertura e épocas de sobressemeadura. E. coracana apresentou o maior número de plantas emergidas (Tabela 1), com exceção da primeira época de sobressemeadura, em que apresentou desempenho semelhante a B.ruziziensis, e da última, em que P. glaucum apresentou maior emergência aos 15 DAS, que se igualou, no entanto, aos 30 DAS. Esses resultados estão de acordo com Trecenti (2005), que também observou, na região de Planaltina, DF, maior índice de germinação dessa espécie em relação a B. ruziziensis, $B$. brizantha cv. Marandu e B. brizantha cv. Xaraés, em sobressemeadura na soja. O percentual de emergência é o primeiro requisito para se viabilizar a recomendação de dada espécie para uso em sobressemeadura. Portanto, E. coracana é uma espécie que apresenta elevada adequação a essa tecnologia, no que se refere a esta característica.

$P$. glaucum também apresentou boa capacidade de germinação na superfície do solo, ao se considerarem os resultados de todas as épocas de sobressemeadura (Tabela 1). O tamanho reduzido das sementes dessas duas espécies proporciona maior superfície específica de contato da semente com o solo, o que favorece a germinação. Entretanto, como as sementes menores são mais leves, elas estão sujeitas ao escoamento superficial pela enxurrada, e isto deve ser considerado na escolha da espécie de cobertura.

Tabela 1. Emergência e altura das plantas de cobertura sobressemeadas à soja implantada em quatro épocas, aos 15 e 30 dias após a sobressemeadura (DAS) ${ }^{(1)}$.

\begin{tabular}{|c|c|c|c|c|}
\hline \multirow[t]{2}{*}{ Espécie de cobertura } & \multicolumn{4}{|c|}{ Épocas de sobressemeadura } \\
\hline & $30 / 1 / 2006$ & $13 / 2 / 2006$ & $22 / 2 / 2006$ & $14 / 3 / 2006$ \\
\hline & \multicolumn{4}{|c|}{ Número de plantas por $\mathrm{m}^{2}$ aos 15 DAS } \\
\hline B. decumbens & $13,27 \mathrm{Ba}$ & $0,80 \mathrm{Bb}$ & $13,85 \mathrm{Da}$ & $12,25 \mathrm{CDa}$ \\
\hline B. ruziziensis & $32,73 \mathrm{Aa}$ & $1,15 \mathrm{Bb}$ & $25,68 \mathrm{Ca}$ & $21,08 \mathrm{Ba}$ \\
\hline B. brizantha & $12,00 \mathrm{Ba}$ & $1,26 \mathrm{Bb}$ & $10,50 \mathrm{Da}$ & $9,33 \mathrm{Da}$ \\
\hline E. coracana & $30,95 \mathrm{Ab}$ & $15,93 \mathrm{Ac}$ & $58,30 \mathrm{Aa}$ & $37,50 \mathrm{Ba}$ \\
\hline P. glaucum & $12,43 \mathrm{Bc}$ & $4,73 \mathrm{Bd}$ & $40,00 \mathrm{Bb}$ & $84,00 \mathrm{Aa}$ \\
\hline \multirow[t]{2}{*}{ S. bicolor x S. sudanense } & $8,35 \mathrm{Cbc}$ & $1,58 \mathrm{Bc}$ & $7,03 \mathrm{Db}$ & $24,00 \mathrm{Ba}$ \\
\hline & \multicolumn{4}{|c|}{ Número de plantas por $\mathrm{m}^{2}$ aos 30 DAS } \\
\hline B. decumbens & $17,07 \mathrm{Ba}$ & $4,42 \mathrm{BCb}$ & $8,92 \mathrm{Cab}$ & $9,67 \mathrm{BCab}$ \\
\hline B. ruziziensis & $39,00 \mathrm{Aa}$ & $5,08 \mathrm{BCb}$ & $26,42 \mathrm{Ba}$ & $17,67 \mathrm{Ba}$ \\
\hline B. brizantha & $10,58 \mathrm{Ba}$ & $2,73 \mathrm{Cb}$ & $13,75 \mathrm{Ca}$ & $8,00 \mathrm{Cab}$ \\
\hline E. coracana & $35,33 \mathrm{Ab}$ & $44,58 \mathrm{Ab}$ & $74,00 \mathrm{Aa}$ & $55,25 \mathrm{Aab}$ \\
\hline P. glaucum & $18,00 \mathrm{Bb}$ & $11,84 \mathrm{Bb}$ & $17,34 \mathrm{BCb}$ & $60,67 \mathrm{Aa}$ \\
\hline \multirow{2}{*}{ S. bicolor x S. sudanense } & $11,50 \mathrm{Bab}$ & $1,42 \mathrm{Cc}$ & $9,42 \mathrm{Cbc}$ & $21,17 \mathrm{Ba}$ \\
\hline & \multicolumn{4}{|c|}{ Altura de plantas aos 30 DAS $(\mathrm{cm})$} \\
\hline B. decumbens & $11,63 \mathrm{BCb}$ & $9,64 \mathrm{Cb}$ & $19,73 \mathrm{Ba}$ & $18,51 \mathrm{Ca}$ \\
\hline B. ruziziensis & $9,10 \mathrm{Cb}$ & $8,33 \mathrm{Cb}$ & $15,66 \mathrm{Ba}$ & $17,47 \mathrm{Ca}$ \\
\hline B. brizantha & $11,68 \mathrm{BCbc}$ & $10,47 \mathrm{Cc}$ & $17,14 \mathrm{Bab}$ & $17,68 \mathrm{Ca}$ \\
\hline E. coracana & $14,94 \mathrm{BCb}$ & $17,53 \mathrm{Bab}$ & $17,93 \mathrm{Bab}$ & $21,79 \mathrm{Ca}$ \\
\hline P. glaucum & $19,57 \mathrm{Ac}$ & $22,08 \mathrm{ABbc}$ & $26,79 \mathrm{Ab}$ & $36,58 \mathrm{Ba}$ \\
\hline S. bicolor x S. sudanense & $16,48 \mathrm{ABc}$ & $26,92 \mathrm{Ab}$ & $31,21 \mathrm{Ab}$ & $43,36 \mathrm{Aa}$ \\
\hline
\end{tabular}

${ }^{(1)}$ Médias seguidas por letras iguais, maiúsculas nas colunas e minúsculas nas linhas, não diferem entre si pelo teste de Tukey, a $5 \%$ de probabilidade. 
B. ruziziensis, entre as braquiárias, foi a mais adaptada à emergência em superfície, contudo, com resultados iguais a $B$. decumbens e $B$. brizanhta aos 15 DAS, na segunda época de sobressemeadura, e semelhante apenas a $B$. decumbens aos 30 DAS, na segunda e na última época. Esses resultados também estão de acordo com Trecenti (2005), que obteve melhores resultados de emergência com $B$. ruziziensis. Entretanto, B. brizantha e B. decumbens também apresentaram germinação satisfatória, com médias acima de 8 plantas $\mathrm{m}^{-2}$, superiores à recomendação de 6 plantas $\mathrm{m}^{-2}$ (Kluthcouski \& Aidar, 2003) para estabelecimento e cobertura do solo, satisfatórios por parte das braquiárias em SPD no Cerrado. De maneira geral, o híbrido Cober Crop posicionou-se entre as menores médias de emergência, ao longo das diferentes épocas de sobressemeadura e de avaliação.

A época de sobressemeadura influenciou a emergência das plantas de cobertura nas avaliações aos 15 e 30 DAS. A segunda época de sobressemeadura apresentou as menores médias de estande, em todas as plantas de cobertura, em razão da maior matocompetição, mesmo com adoção da dessecação de manejo, realizada no cultivo da soja. A ocorrência de chuvas, relativamente próximo à aplicação dos herbicidas de pós-emergência na soja, contribuiu para o baixo controle de plantas daninhas nessa época. Durante as quatro épocas de sobressemeadura, não ocorreram veranicos, o que contribuiu para a terceira e quarta época alcançarem estande similar à primeira época.

As plantas de cobertura, na presença de intensa radiação solar e baixa umidade superficial do solo, sofreram crestamento do coleóptilo e da radícula, o que resultou na morte de plântulas. Esse fenômeno explica o baixo estande do híbrido Cober Crop, na segunda época de sobressemeadura, e permite inferir sobre o maior risco que essa espécie apresenta, quando o estádio fenológico $\mathrm{R}_{7}$ da soja coincide com períodos de baixa pluviosidade. Para algumas das espécies, notou-se redução no número de plantas emergidas, contabilizadas na avaliação de 15 DAS para 30 DAS, na terceira e na quarta épocas de sobressemeadura (Tabela 1), causada, possivelmente, pela competição intra-específica das plantas de cobertura, e pelo aumento na emergência de plantas daninhas (Cenchrus echinatus e Alternanthera tenella), nesse intervalo.

Quanto à altura de plantas aos 30 DAS, houve interação significativa entre as plantas de cobertura e as épocas de sobressemeadura. As braquiárias, independentemente da época de sobressemeadura, e E. coracana nas três primeiras épocas, atingiram a altura máxima de $18,51 \mathrm{~cm}$. Como a altura de inserção da primeira vagem na soja situa-se em torno de 15 a $20 \mathrm{~cm}$ (Peixoto \& Souza, 2002), a altura dessas espécies não seria empecilho à colheita mecanizada da soja. Por outro lado, P. glaucum e o híbrido Cober Crop apresentaram rápido crescimento inicial, e chegaram a 37 e $43 \mathrm{~cm}$ de altura aos 30 DAS, respectivamente, o que deve comprometer a colheita mecânica. Esta interferência pode ser ainda maior, caso haja atraso na colheita da soja (Kluthcouski \& Aidar, 2003).

$\mathrm{O}$ efeito da época de sobressemeadura, sobre a altura das plantas de cobertura, foi maior na terceira e na quarta épocas, em que as maiores alturas das plantas podem ser atribuídas às condições adequadas de umidade do solo, nos períodos pré e póssobressemeadura na soja, que possibilitaram maior velocidade de emergência e crescimento inicial das plantas de cobertura.

Houve interação significativa entre as plantas de cobertura e as épocas de sobressemeadura, na variável taxa de cobertura do solo (Tabela 2). E. coracana e $P$. glaucum destacaram-se na capacidade de cobrir o solo, em todas as épocas de sobressemeadura, aos 30 DAS. Comparando-se à testemunha, a cobertura do solo promovida por essas espécies aumentou aproximadamente $400 \%$. Este resultado está de acordo com boa capacidade de germinação dessas espécies na superfície do solo, observada no presente trabalho, porém diverge de Sodré Filho et al. (2004), que observaram desempenho inferior de P. glaucum, semeado em sucessão às culturas anuais na entressafra do Cerrado. Aos 75 DAS, P. glaucum e E. coracana apresentaram valores de cobertura do solo, em geral, inferiores ou iguais aos observados nas braquiárias, em razão do maior desenvolvimento dessas últimas após 30 DAS. Portes et al. (2000) também observaram significativo crescimento das braquiárias, após 45 dias de emergência, com grande aumento na taxa de emissão de folhas e perfilhos.

A maior emergência de plântulas, freqüente nas duas últimas épocas de sobressemeadura (Tabela 1), contribuiu para o aumento da capacidade das plantas de cobertura em promover a cobertura do solo (Tabela 2), o que pode contribuir para a redução do processo erosivo após a colheita da cultura anual (Dedececk et al., 1986). As plantas de cobertura que apresentaram menores oscilações na cobertura do solo, dentro das épocas de 
sobressemeadura, foram B. brizantha, B. decumbens e $B$. ruziziensis, em razão de essas espécies perfilharem e crescerem de forma prostrada ao solo.

As braquiárias destacaram-se quanto à cobertura do solo, e alcançaram $100 \%$ de cobertura nos meses de setembro e outubro (Tabela 2), independentemente da época de sobressemeadura. Essas espécies apresentam maior tolerância ao estresse hídrico, observado na entressafra, por ser perenes, além de alta produção de fitomassa, o que resultou na total cobertura do solo. O híbrido Cober Crop também apresentou boa cobertura do solo, em razão da alta produção de fitomassa. P. glaucum e E. coracana apresentaram reduzida cobertura do solo nesse período, em razão da elevada taxa de decomposição de seus resíduos no solo. Esses resultados estão de acordo com Timossi et al. (2007), que também observaram excelente cobertura do solo com braquiárias e acelerada decomposição da palhada do milheto.

P. glaucum e E. coracana apresentaram maior cobertura do solo quando cultivados nas últimas épocas, em razão do melhor estande observado nelas (Tabela 1). Além disso, a senescência dessas espécies ocorreu mais tardiamente nas terceira e quarta épocas de sobressemeadura, o que contribuiu para retardar e diminuir o processo de decomposição da fitomassa. A testemunha aumentou a cobertura do solo entre os meses de setembro e outubro, em razão da emergência de plantas espontâneas após as primeiras chuvas, situação indesejável por aumentar o banco de sementes no solo e ocasionar problemas para seu posterior controle (Carbonari et al., 2003; Pires et al., 2008). Quanto à

Tabela 2. Cobertura do solo por plantas de cobertura sobressemeadas à soja implantada em quatro épocas, aos 30 e 75 dias após a sobressemeadura (DAS), e nos meses de setembro e outubro ${ }^{(1)}$.

\begin{tabular}{|c|c|c|c|c|}
\hline \multirow[t]{2}{*}{ Espécie de cobertura } & \multicolumn{4}{|c|}{ Épocas de sobressemeadura } \\
\hline & $30 / 1 / 2006$ & $13 / 2 / 2006$ & $22 / 2 / 2006$ & $14 / 3 / 2006$ \\
\hline & \multicolumn{4}{|c|}{ Cobertura do solo (\%) aos 30 DAS } \\
\hline B. decumbens & $28,75 \mathrm{BCa}$ & $9,37 \mathrm{Bb}$ & $43,12 \mathrm{BCDa}$ & $31,25 \mathrm{CDa}$ \\
\hline B. ruziziensis & $38,75 \mathrm{ABb}$ & $7,50 \mathrm{Bc}$ & $70,00 \mathrm{Aa}$ & $53,75 \mathrm{Bb}$ \\
\hline B. brizantha & $31,25 \mathrm{BCa}$ & $10,63 \mathrm{Bb}$ & $34,38 \mathrm{Da}$ & $34,38 \mathrm{BCa}$ \\
\hline E. coracana & $55,00 \mathrm{Ab}$ & $46,87 \mathrm{Ab}$ & $61,25 \mathrm{ABCb}$ & $86,88 \mathrm{Aa}$ \\
\hline P. glaucum & $35,00 \mathrm{ABc}$ & $36,25 \mathrm{Ac}$ & $64,38 \mathrm{ABb}$ & $95,63 \mathrm{Aa}$ \\
\hline S. bicolor x S. sudanense & $20,00 \mathrm{BCc}$ & $11,25 \mathrm{Bc}$ & $42,50 \mathrm{CDb}$ & $83,75 \mathrm{Aa}$ \\
\hline \multirow[t]{2}{*}{ Testemunha } & $12,25 \mathrm{Ca}$ & $10,50 \mathrm{Ba}$ & $8,00 \mathrm{Ea}$ & $9,50 \mathrm{Da}$ \\
\hline & \multicolumn{4}{|c|}{ Cobertura do solo (\%) aos 75 DAS } \\
\hline B. decumbens & $89,38 \mathrm{Aba}$ & $66,25 \mathrm{BCb}$ & $90,63 \mathrm{Aba}$ & $80,00 \mathrm{ABak}$ \\
\hline B. ruziziensis & $100,00 \mathrm{Aa}$ & $90,63 \mathrm{Aa}$ & $100,00 \mathrm{Aa}$ & $89,38 \mathrm{Aa}$ \\
\hline B. brizantha & $100,00 \mathrm{Aa}$ & $50,63 \mathrm{BCb}$ & $87,50 \mathrm{Aba}$ & $63,13 \mathrm{Bb}$ \\
\hline E. coracana & $77,50 \mathrm{Bb}$ & $70,63 \mathrm{ABb}$ & $75,00 \mathrm{Bb}$ & $92,50 \mathrm{Aa}$ \\
\hline P. glaucum & $54,38 \mathrm{Cc}$ & $52,50 \mathrm{BCc}$ & $74,38 \mathrm{Bb}$ & $96,88 \mathrm{Aa}$ \\
\hline S. bicolor x $S$. sudanense & $46,88 \mathrm{CDb}$ & $48,13 \mathrm{Cb}$ & $88,13 \mathrm{Aba}$ & $100,00 \mathrm{Aa}$ \\
\hline \multirow[t]{2}{*}{ Testemunha } & $26,80 \mathrm{Da}$ & $22,00 \mathrm{Da}$ & $18,25 \mathrm{Ca}$ & $17,50 \mathrm{Ca}$ \\
\hline & \multicolumn{4}{|c|}{ Cobertura do solo (\%) em setembro } \\
\hline B. decumbens & $100,00 \mathrm{Aa}$ & $100,00 \mathrm{Aa}$ & $100,00 \mathrm{Aa}$ & $100,00 \mathrm{Aa}$ \\
\hline B. ruziziensis & $100,00 \mathrm{Aa}$ & $100,00 \mathrm{Aa}$ & $100,00 \mathrm{Aa}$ & $100,00 \mathrm{Aa}$ \\
\hline B. brizantha & $91,25 \mathrm{Aa}$ & $100,00 \mathrm{Aa}$ & $100,00 \mathrm{Aa}$ & $100,00 \mathrm{Aa}$ \\
\hline E. coracana & $62,50 \mathrm{Ba}$ & $68,25 \mathrm{Ba}$ & $67,25 \mathrm{Ca}$ & $71,25 \mathrm{CDa}$ \\
\hline P. glaucum & $53,25 \mathrm{BCc}$ & $71,25 \mathrm{Bb}$ & $84,75 \mathrm{Ba}$ & $84,00 \mathrm{BCa}$ \\
\hline S. bicolor x $S$. sudanense & $90,00 \mathrm{Aa}$ & $75,00 \mathrm{Bb}$ & $92,50 \mathrm{ABa}$ & $95,00 \mathrm{Aba}$ \\
\hline \multirow[t]{2}{*}{ Testemunha } & $47,50 \mathrm{Cc}$ & $52,25 \mathrm{Cb}$ & $58,75 \mathrm{Cbc}$ & $69,00 \mathrm{Da}$ \\
\hline & \multicolumn{4}{|c|}{ Cobertura do solo (\%) em outubro } \\
\hline B. decumbens & $100,00 \mathrm{Aa}$ & $100,00 \mathrm{Aa}$ & $100,00 \mathrm{Aa}$ & $100,00 \mathrm{Aa}$ \\
\hline B. ruziziensis & $100,00 \mathrm{Aa}$ & $100,00 \mathrm{Aa}$ & $100,00 \mathrm{Aa}$ & $100,00 \mathrm{Aa}$ \\
\hline B. brizantha & $100,00 \mathrm{Aa}$ & $100,00 \mathrm{Aa}$ & $100,00 \mathrm{Aa}$ & $100,00 \mathrm{Aa}$ \\
\hline E. coracana & $63,75 \mathrm{Cb}$ & $66,75 \mathrm{Bb}$ & $59,50 \mathrm{Bb}$ & $84,75 \mathrm{Ba}$ \\
\hline P. glaucum & $48,50 \mathrm{Dc}$ & $68,25 \mathrm{Bb}$ & $68,50 \mathrm{Bb}$ & $84,00 \mathrm{Ba}$ \\
\hline S. bicolor x S. sudanense & $89,00 \mathrm{ABa}$ & $68,25 \mathrm{Bb}$ & $92,00 \mathrm{Aa}$ & $97,75 \mathrm{Aa}$ \\
\hline Testemunha & $78,00 \mathrm{Bb}$ & $79,50 \mathrm{Bb}$ & $90,00 \mathrm{Aa}$ & $87,00 \mathrm{ABak}$ \\
\hline
\end{tabular}

${ }^{(1)}$ Médias seguidas por letras iguais, maiúsculas nas colunas e minúsculas nas linhas, não diferem entre si pelo teste de Tukey, a 5\% de probabilidade. 
B. brizantha, B. ruziziensis, B. decumbens e o híbrido Cober Crop, o atraso na semeadura da soja não interferiu na cobertura do solo na entressafra, o que aponta essas espécies como opção de sobressemeadura na soja, em épocas mais tardias, desde que não ocorram veranicos durante a emergência e o estabelecimento de plantas. A menor cobertura do solo observada na segunda época de sobressemeadura do híbrido Cober Crop está relacionada à matocompetição durante seu estabelecimento.

$\mathrm{Na}$ produção de fitomassa fresca e seca, durante a entressafra, houve interação significativa entre as plantas de cobertura e épocas de sobressemeadura (Tabela 3). As braquiárias e o híbrido Cober Crop destacaram-se com produções superiores a $12 \mathrm{Mg} \mathrm{ha}^{-1}$ de fitomassa seca, no mês de maio (início da entressafra), aos 100 DAS, na primeira época de sobressemeadura. Essa quantidade de fitomassa seca, superior a $11 \mathrm{Mg} \mathrm{ha}^{-1}$, segundo Alvarenga et al.(2001), é suficiente para compensar a alta taxa de decomposição que ocorre nas regiões tropicais. Nos meses de maio, junho e outubro, apenas o híbrido Cober Crop esteve sempre entre as espécies com maior produção de fitomassa seca, independentemente da época de sobressemeadura, o que caracteriza esta espécie como alternativa altamente viável para a produção de palhada no Cerrado, em sobressemeadura, se contornado o problema da elevada altura das plantas, por ocasião da colheita da soja. P. glaucum e E. coracana apresentaram significativo acúmulo de fitomassa apenas no início da entressafra (maio), em algumas épocas de sobressemeadura. Lemos et al. (2003), Gazetta et al. (2005) e Teixeira et al. (2005) observaram grande produção de fitomassa por parte do milheto, cultivado na entressafra. No mês de junho e outubro, essas espécies apresentaram reduções de fitomassa, em razão da elevada taxa de decomposição, após a senescência das plantas. No caso do milheto, esses resultados corroboram os de Timossi et al. (2007).

No período entre os meses de junho e outubro, as braquiárias se recuperaram em relação ao híbrido

Tabela 3. Produção de fitomassa fresca (FV) e seca (FS), por plantas de cobertura sobressemeadas à soja implantada em quatro épocas, determinada na primeira quinzena do mês de maio e na segunda quinzena dos meses de junho e outubro ${ }^{(1)}$.

\begin{tabular}{|c|c|c|c|c|c|c|c|c|}
\hline \multirow[t]{3}{*}{ Planta de cobertura } & \multicolumn{8}{|c|}{ Época de sobressemeadura } \\
\hline & \multicolumn{2}{|c|}{$30 / 1 / 2006$} & \multicolumn{2}{|c|}{$13 / 2 / 2006$} & \multicolumn{2}{|c|}{$22 / 2 / 2006$} & \multicolumn{2}{|c|}{$14 / 3 / 2006$} \\
\hline & FV & FS & FV & FS & FV & FS & FV & FS \\
\hline & \multicolumn{8}{|c|}{ Maio $\left(\mathrm{Mg} \mathrm{ha}^{-1}\right)$} \\
\hline B. decumbens & $30,40 \mathrm{Ba}$ & $13,96 \mathrm{Ba}$ & $12,85 \mathrm{ABb}$ & $3,50 \mathrm{Bb}$ & $11,00 \mathrm{BCb}$ & $3,55 \mathrm{Bb}$ & $7,35 \mathrm{Bb}$ & $2,10 \mathrm{Cb}$ \\
\hline B. ruziziensis & $49,80 \mathrm{Aa}$ & $13,50 \mathrm{Ba}$ & $19,25 \mathrm{ABb}$ & $5,25 \mathrm{ABb}$ & $20,65 \mathrm{ABb}$ & $5,05 \mathrm{Bb}$ & $10,75 \mathrm{Bc}$ & $2,90 \mathrm{Cb}$ \\
\hline B. brizantha & $42,90 \mathrm{Aa}$ & $11,10 \mathrm{BCa}$ & $9,00 \mathrm{Bb}$ & $3,50 \mathrm{Bb}$ & $8,85 \mathrm{Cb}$ & $2,59 \mathrm{Bb}$ & $8,45 \mathrm{Bb}$ & $2,15 \mathrm{Cb}$ \\
\hline E. coracana & $24,20 \mathrm{BCa}$ & $7,70 \mathrm{CDa}$ & $23,65 \mathrm{Aa}$ & $7,15 \mathrm{ABab}$ & $13,80 \mathrm{BCb}$ & $3,65 \mathrm{Bc}$ & $14,55 \mathrm{Bb}$ & $4,35 \mathrm{Cbc}$ \\
\hline P. glaucum & $28,65 \mathrm{Bb}$ & $8,75 \mathrm{Cbc}$ & $20,85 \mathrm{Ab}$ & $6,00 \mathrm{Abc}$ & $25,15 \mathrm{Ab}$ & $10,65 \mathrm{Aab}$ & $41,35 \mathrm{Aa}$ & $12,30 \mathrm{Ba}$ \\
\hline S. bicolor x S. sudanense & $49,85 \mathrm{Aa}$ & $23,75 \mathrm{Aa}$ & $23,20 \mathrm{Ab}$ & $8,90 \mathrm{Ac}$ & $26,85 \mathrm{Ab}$ & $11,50 \mathrm{Ac}$ & $43,30 \mathrm{Aa}$ & $16,65 \mathrm{Ab}$ \\
\hline \multirow[t]{2}{*}{ Testemunha } & $15,77 \mathrm{Ca}$ & $4,05 \mathrm{Da}$ & $9,10 \mathrm{Bab}$ & $3,35 \mathrm{Ba}$ & $9,05 \mathrm{Cab}$ & $2,45 \mathrm{Ba}$ & $6,60 \mathrm{Bb}$ & $1,95 \mathrm{Ca}$ \\
\hline & \multicolumn{8}{|c|}{ Junho $\left(\mathrm{Mg} \mathrm{ha}^{-1}\right)$} \\
\hline B. decumbens & $17,87 \mathrm{ABa}$ & $6,20 \mathrm{ABCa}$ & $15,85 \mathrm{Aa}$ & $5,41 \mathrm{ABCa}$ & $14,49 \mathrm{Aa}$ & $4,60 \mathrm{ABab}$ & $8,68 \mathrm{Bb}$ & $2,86 \mathrm{BCb}$ \\
\hline B. ruziziensis & $17,84 \mathrm{ABab}$ & $6,21 \mathrm{ABCa}$ & $20,66 \mathrm{Aa}$ & $6,93 \mathrm{Aba}$ & $14,04 \mathrm{Abc}$ & $3,91 \mathrm{ABb}$ & $9,72 \mathrm{Bc}$ & $2,76 \mathrm{BCb}$ \\
\hline B. brizantha & $21,77 \mathrm{Aa}$ & $7,24 \mathrm{Aa}$ & $16,19 \mathrm{Ab}$ & $5,69 \mathrm{ABCa}$ & $12,62 \mathrm{ABbc}$ & $3,77 \mathrm{ABb}$ & $8,62 \mathrm{Bc}$ & $2,76 \mathrm{BCb}$ \\
\hline E. coracana & $6,25 \mathrm{Ca}$ & 4,61BCDa & $5,10 \mathrm{Ba}$ & $4,42 \mathrm{BCDa}$ & $5,43 \mathrm{Ca}$ & $3,29 \mathrm{Ba}$ & $10,05 \mathrm{Ba}$ & $4,07 \mathrm{BCa}$ \\
\hline P. glaucum & $4,20 \mathrm{Cb}$ & $3,96 \mathrm{CDa}$ & $4,10 \mathrm{Bb}$ & $3,27 \mathrm{CDa}$ & $6,30 \mathrm{BCab}$ & $4,40 \mathrm{ABa}$ & $8,70 \mathrm{Ba}$ & $4,72 \mathrm{Ba}$ \\
\hline S. bicolor $\times$ S. sudanense & $14,44 \mathrm{Bb}$ & $7,04 \mathrm{ABa}$ & $15,24 \mathrm{Aab}$ & 7,49Aa & $17,17 \mathrm{Aab}$ & $6,06 \mathrm{Aa}$ & $20,14 \mathrm{Aa}$ & $7,55 \mathrm{Aa}$ \\
\hline \multirow[t]{2}{*}{ Testemunha } & $2,87 \mathrm{Ca}$ & $2,65 \mathrm{Da}$ & $2,70 \mathrm{Ba}$ & $2,00 \mathrm{Da}$ & $3,50 \mathrm{Ca}$ & $2,10 \mathrm{Ba}$ & $3,36 \mathrm{Ba}$ & $1,75 \mathrm{Ca}$ \\
\hline & \multicolumn{8}{|c|}{ Outubro $\left(\mathrm{Mg} \mathrm{ha}^{-1}\right)$} \\
\hline B. decumbens & $29,55 \mathrm{Aa}$ & $9,85 \mathrm{Aa}$ & $14,83 \mathrm{Ab}$ & $6,03 \mathrm{ABb}$ & $17,59 \mathrm{Ab}$ & $6,91 \mathrm{Ab}$ & $14,05 \mathrm{Ab}$ & $4,52 \mathrm{BCc}$ \\
\hline B. ruziziensis & $15,76 \mathrm{Ba}$ & $7,25 \mathrm{Ba}$ & $18,50 \mathrm{Aa}$ & $7,16 \mathrm{Aa}$ & $16,17 \mathrm{Aa}$ & $5,38 \mathrm{Bab}$ & $9,23 \mathrm{Ab}$ & $3,33 \mathrm{Cc}$ \\
\hline B. brizantha & $25,82 \mathrm{Aa}$ & $9,95 \mathrm{Aa}$ & $11,52 \mathrm{ABb}$ & $5,17 \mathrm{Bbc}$ & $16,94 \mathrm{Ab}$ & $5,66 \mathrm{ABb}$ & $11,96 \mathrm{Ab}$ & $4,12 \mathrm{BCc}$ \\
\hline E. coracana & $3,66 \mathrm{Da}$ & $3,06 \mathrm{Cab}$ & $4,08 \mathrm{Ba}$ & $3,42 \mathrm{Ca}$ & $2,82 \mathrm{Ba}$ & $2,20 \mathrm{Cb}$ & $3,98 \mathrm{BCa}$ & $3,49 \mathrm{Ca}$ \\
\hline P. glaucum & $3,20 \mathrm{Da}$ & $2,81 \mathrm{Cb}$ & $3,03 \mathrm{Ba}$ & $2,88 \mathrm{Cb}$ & $3,42 \mathrm{Ba}$ & $2,92 \mathrm{Cb}$ & $5,55 \mathrm{Ba}$ & $5,20 \mathrm{Ba}$ \\
\hline S. bicolor $\mathrm{x}$ S. sudanense & $12,22 \mathrm{BCa}$ & $8,83 \mathrm{Aa}$ & $12,80 \mathrm{Aa}$ & $6,94 \mathrm{Ab}$ & $10,80 \mathrm{ABa}$ & $5,80 \mathrm{ABc}$ & $15,96 \mathrm{Aa}$ & $7,43 \mathrm{Ab}$ \\
\hline Testemunha & $3,77 \mathrm{CDa}$ & $2,82 \mathrm{Ca}$ & $3,17 \mathrm{Ba}$ & $2,66 \mathrm{Ca}$ & $7,57 \mathrm{Ba}$ & $2,01 \mathrm{Cab}$ & $1,75 \mathrm{Ca}$ & $1,35 \mathrm{Db}$ \\
\hline
\end{tabular}

${ }^{(1)}$ Médias seguidas por letras iguais, maiúsculas nas colunas e minúsculas nas linhas, não diferem entre si pelo teste de Tukey, a 5\% de probabilidade, para fitomassa fresca e fitomassa seca separadamente. 
Cober Crop, e apresentaram também elevada produção de fitomassa seca, o que foi possibilitado pelo ciclo perene e pela capacidade de essas espécies acumularem fitomassa, em condições de estresse hídrico (Kluthcouski \& Aidar, 2003). A redução da fitomassa das espécies de Brachiaria spp., observada entre os meses de maio e junho, na primeira época de sobressemeadura, ocorreu em razão do florescimento e da granação nesse período e causou o carreamento de carboidratos para as sementes. Após o início das chuvas, em outubro, as braquiárias rebrotaram, o que se refletiu no aumento de fitomassa em relação ao mês de junho; essa característica aponta essas espécies como boas alternativas para o aumento no aporte de matéria orgânica no solo. Sodré Filho et al. (2004) também encontraram benefícios da rebrota de plantas de cobertura no aumento da fitomassa e cobertura do solo, com o início das chuvas de verão.

A época de sobressemeadura também interferiu na produção de fitomassa pelas plantas de cobertura. O maior aproveitamento do aporte hídrico e do fotoperíodo na primeira época de sobressemeadura contribuiu para o maior desenvolvimento da B. brizantha. Trecenti (2005) observou, aos 73 DAS, fitomassa seca em torno de 1,5 e $3,4 \mathrm{Mg} \mathrm{ha}^{-1} \mathrm{em}$ B. brizantha e B. ruziziensis, respectivamente. Os resultados obtidos são inferiores aos observados neste trabalho. O híbrido Cober Crop foi pouco influenciado pela época de sobressemeadura na soja, com possibilidades de ser implantado mais tardiamente, sem prejuízo de seu crescimento. E. coracana sofreu influência das épocas de sobressemeadura apenas em maio, quando a primeira época sobressaiu-se, com produção de maior quantidade de fitomassa. $P$. glaucum apresentou a maior fitomassa na quarta época de sobressemeadura, no mês de maio, em razão do atraso em seu florescimento e frutificação. No mês de outubro, essa época de sobressemeadura proporcionou menor tombamento das plantas de milheto, ao longo da entressafra, o que resultou em menor contato das plantas com o solo e redução na decomposição.

\section{Conclusões}

1. Pennisetum glaucum e Eleusine coracana são espécies com elevado índice de emergência em sobressemeadura na soja, e entre as plantas de cobertura do gênero Brachiaria, destaca-se a B. ruziziensis.
2. B. ruziziensis, B. brizantha, B. decumbens e E. coracana, semeados no estádio $\mathrm{R}_{7}$ da soja, apresentam altura de plantas adequada para a colheita mecânica da soja.

3. B. ruziziensis, B. brizantha, B. decumbens e o híbrido Cober Crop são as espécies com maior potencial para a produção de fitomassa, com maior persistência na entressafra, independentemente da época de sobressemeadura.

4. A primeira, terceira e quarta épocas de sobressemeadura, na ausência de veranicos, apresentaram crescimento inicial satisfatório de B. ruziziensis, B. brizantha, B. decumbens, E. coracana e do híbrido Cober Crop.

\section{Agradecimentos}

À Coordenação de Aperfeiçoamento de Pessoal de Nível Superior, pela concessão de bolsa; à Fundação Agrisus, pelo apoio financeiro.

\section{Referências}

ALVARENGA, R.C.; COSTA, L.M.; MOURA FILHO, W.; REGAZZI, A.J. Características de alguns adubos verdes de interesse para a conservação e recuperação de solos. Pesquisa Agropecuária Brasileira, v.30, p.175-184, 1995.

ALVARENGA, R.C.; LARA-CABEZAS, W.A.; CRUZ, J.C.; SANTANA, D.P. Plantas de cobertura de solo para sistema plantio direto. Informe Agropecuário, v.22, p.25-36, 2001.

ALVES, A.G.C.; COGO, N.P.; LEVIEN, R. Relações da erosão do solo com a persistência da cobertura morta. Revista Brasileira de Ciência do Solo, v.19, p.127-132, 1995.

AMABILE, R.F.; FANCELLI, A.L.; CARVALHO, A.M. de. Comportamento de espécies de adubos verdes em diferentes épocas de semeadura e espaçamentos na região dos Cerrados. Pesquisa Agropecuária Brasileira, v.35, p.47-54, 2000.

BOER, C.A.; ASSIS, R.L.; SILVA, G.P.; BRAZ, A.J.B.P.; BARROSO, A.L.L.; CARGNELUTTI FILHO, A.; PIRES, F.R. Ciclagem de nutrientes por plantas de cobertura na entressafra em um solo de cerrado. Pesquisa Agropecuária Brasileira, v.42, p.1269-1276, 2007.

CARBONARI, C.A.; MARTINS, D.; TERRA, M.A. Controle de Brachiaria subquadripara e Brachiaria mutica através de diferentes herbicidas aplicados em pós-emergência. Planta Daninha, v.21, p.79-84, 2003.

CERETTA, C.A.; BASSO, C.J.; FLECHA, A.M.T.; PAVINATO, P.S.; VIEIRA, F.C.B.; MAI, M.E.M. Manejo da adubação nitrogenada na sucessão aveia preta/milho, no sistema plantio direto. Revista Brasileira de Ciência do Solo, v.26, p.163-171, 2002.

DEDECECK, R.A.; RESCK, D.V.S.; FREITAS JÚNIOR, E. Perdas de solo, água e nutrientes por erosão em diferentes cultivos sob chuva natural. Revista Brasileira de Ciência do Solo, v.10, p.265-272, 1986. 
GAMA-RODRIGUES, A.C.; GAMA-RODRIGUES, E.F.; BRITO, E.C. Decomposição e liberação de nutrientes de resíduos culturais de plantas de cobertura em Argissolo Vermelho-Amarelo na região Noroeste Fluminense (RJ). Revista Brasileira de Ciência do Solo, v.31, p.1421-1428, 2007.

GAZETTA, D.A.; FORNASIERI FILHO, D.; GIROTTO, F. Composição, produção de matéria seca e cobertura do solo em cultivo exclusivo e consorciado de milheto e crotalária. Acta Scientiarum Agronomy, v.27, p.575-580, 2005.

KLIEMANN, H.J.; BRAZ, A.J.P.B.; SILVEIRA, P.M. Taxas de decomposição de resíduos de espécies de cobertura em Latossolo Vermelho distroférrico. Pesquisa Agropecuária Tropical, v.36, p.2128, 2006.

KLUTHCOUSKI, J.; AIDAR, H. Implantação, condução e resultados obtidos com o sistema Santa-Fé. In: KLUTHCOUSKI, J.; AIDAR, H.; STONE, L.F. Integração lavoura-pecuária. Santo Antônio de Goiás: Embrapa Arroz e Feijão, 2003. p.407-441.

LAL, R.; LOGAN, T.J. Agricultural activities and greenhouse gas emissions from soils of the tropics. In: LAL, R.; KIMBLE, J.M.; LEVINE, E.; STEWART, B.A. (Ed.). Soil management greenhouse effect. Boca Raton: CRC Press, 1995. p.293-307.

LARA-CABEZAS, W.A.R. Sobressemeadura com sementes de milheto revestidas no Triângulo Mineiro-MG: estudo preliminar. Revista Plantio Direto, v.79, p.16-18, 2004.

LEMOS, L.B.; NAKAGAWA, J.; CRUSCIOL, C.A.C.; CHIGNOLI JÚNIOR, W.; SILVA, T.R.B. Influência da época de semeadura e do manejo da parte aérea de milheto sobre a soja em sucessão em plantio direto. Bragantia, v.62, p.405-415, 2003.

PEIXOTO, M.F.; SOUZA, I.F. Efeitos de doses de imazamox e densidades de sorgo (Sorghum bicolor (L.) Moench) em soja (Glycine $\max ($ L.) Merril) sob plantio direto. Ciência e Agrotecnologia, v.26, p.252-258, 2002.

PERIN, A.; SANTOS, R.H.S.; URQUIAGA, S.; GUERRA, J.G.M.; CECON, P.R. Produção de fitomassa, acúmulo de nutrientes e fixação biológica de nitrogênio por adubos verdes em cultivo isolado e consorciado. Pesquisa Agropecuária Brasileira, v.39, p.35-40, 2004.
PIRES, F.R.; ASSIS, R.L.; PROCÓPIO, S.O.; SILVA, G.P.; MORAES, L.L.; RUDOVALHO, M.C.; BOER, C.A. Manejo de plantas de cobertura antecessoras à cultura da soja em plantio direto. Revista Ceres, v.55, p.94-101, 2008.

PORTES, T.A.; CARVALHO, S.I.C.; OLIVEIRA, I.P.; KLUTHCOUSKI, J. Análise do crescimento de uma cultivar de braquiária em cultivo solteiro e consorciado com cereais. Pesquisa Agropecuária Brasileira, v.35, p.1349-1358, 2000.

SILVA, A.C.; FREITAS, F.C.; FERREIRA, L.R.; FREITAS, R.G. Dessecação pré-colheita de soja e Brachiaria brizantha consorciadas com doses reduzidas de graminicida. Pesquisa Agropecuária Brasileira, v.41, p.37-42, 2006.

SODRÉ FILHO, J.; CARDOSO, A.N.; CARMONA, R.; CARVALHO, A.M. Fitomassa e cobertura do solo de culturas de sucessão ao milho na região do Cerrado. Pesquisa Agropecuária Brasileira, v.39, p.327-334, 2004.

STOCKING, M.A. Assessing vegetative cover and management effects. In: LAL, R. (Ed.). Soil erosion research methods. Ankeny: Soil and Water Conservation Society, 1988. p.163-185.

TEIXEIRA, C.M.; CARVALHO, G.J. de C.; FURTINI NETO, A.E.; ANDRADE, M.J.B. de; MARQUES, E.L.S. Produção de biomassa e teor de macronutrientes do milheto, feijão-de-porco e guandu-anão em cultivo solteiro e consorciado. Ciência e Agrotecnologia, v.29, p.93-99, 2005.

TIMOSSI, P.C.; DURIGAN, J.C.; LEITE, G.J. Formação de palhada por braquiárias para adoção do sistema plantio direto. Bragantia, v.66, p.617-622, 2007.

TORRES, J.L.R.; PEREIRA, M.G.; FABIAN, A.J. Produção de fitomassa por plantas de cobertura e mineralização de seus resíduos em plantio direto. Pesquisa Agropecuária Brasileira, v.43, p.421-428, 2008.

TRECENTI, R. Avaliação de características agronômicas de espécies de cobertura vegetal do solo em cultivos de entressafra e sobressemeadura, na região central do Cerrado. 2005. 118p. Dissertação (Mestrado) - Universidade de Brasília, Brasília.

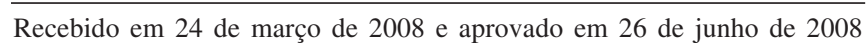

